\title{
POLÍTICAS PÚBLICAS DE INCENTIVO AO LIVRO, LEITURA E LITERATURA
}

Roberto Belo

\section{RESUMO}

Este trabalho visa a discutir algumas das principais leis e diretrizes de incentivo ao livro, à leitura e à literatura presentes na sociedade brasileira. Com pouco mais de 202,7 milhóes de habitantes, considerado a sétima maior economia do mundo e o quinto maior país em extensão territorial, o Brasil é um dos países mais desiguais do planeta, sobretudo na democratização de acesso aos bens culturais, como as bibliotecas.

PALAVRAS-CHAVE: letramento literário no Brasil; desigualdade social; políticas públicas educacionais.

Em princípio, só numa sociedade igualitária os produtos literários poderão circular sem barreiras, e neste domínio a situação é particularmente dramática em países como o Brasil, onde a maioria da população é analfabeta, ou quase, e vive em condiçôes que não permitem a margem de lazer indispensável à leitura. [...] Pelo que sabemos, quando há um esforço real de igualitarização há aumento sensível do hábito de leitura, e portanto difusão crescente das obras. (CANDIDO, 2004, p. 186-187)

\section{Casa-grande e senzala: as contradições brasileiras}

Brasil ainda está longe de se tornar um país de leitores, sobretudo de leitores proficientes; mas estamos avançando. Uma prova disso é o investimento por parte do Governo Federal, desde 1937, em po- 
líticas públicas relacionadas ao livro, à leitura e à literatura, como o Programa Nacional Biblioteca da Escola (PNBE), que é o mais recente e o mais robusto de todos, no quesito literatura. Ainda assim, vê-se a falta de vontade política efetiva, organizacional e sistemática de combate aos baixos índices educacionais que afetam o país, ainda mais quando nos restringimos ao letramento literário. Falta comprometimento de todos os envolvidos, principalmente da Família e do Estado, e ações conjuntas e integradas dos setores Públicos, Privados e ONGs para que se rompa a barreira da ignorância leitora. Os dados de leitura nesse país são alarmantes, e isso não é de hoje, consequentemente, tem-se uma nação com altos índices de desaprovação em tudo quanto for relacionado ao desenvolvimento da terra, do homem e do seu trabalho.

Segundo dados do Instituto Brasileiro de Geografia e Estatística (IBGE), somos 202,7 milhóes de brasileiros e brasileiras (BRASIL, 2014a), a sétima maior economia do mundo (BRASIL, 2014b) e o quinto maior país em extensão territorial. Mas, infelizmente, somos também um dos países mais desiguais do planeta. Relatório publicado pelo Programa das Naçóes Unidas para o Desenvolvimento (PNUD, 2014) explica que o Brasil, apesar de ter melhorado nesses últimos anos, graças a programas como o Bolsa Família (PNUD, 2014, p. 89), ainda possui altos índices de desigualdade social, sobretudo em educação e expectativa de vida, estamos, inclusive, abaixo da média da América Latina. E, tratando-se da diferença e distanciamento entre ricos e pobres, o país fica atrás no ranking apenas de países muito menores e menos ricos. Nosso Índice de Desenvolvimento Humano (IDH) melhorou, avançamos uma posição no ranking mundial, passando do $80^{\circ}$ lugar em 2012 (IDH de 0,742) para o 79 em 2013 (IDH 0,744) numa lista de $187^{\circ}$ países. O Brasil é um verdadeiro paradoxo, tanto que chega a confundir seus próprios habitantes.

A economia brasileira, quer dizer, $75 \%$ da riqueza do Brasil, está concentrada nas mãos de pouco mais de $10 \%$ da população. Partindo de dados reais disponibilizados pela Receita Federal do Brasil, através das declaraçóes do Imposto de Renda Pessoa Física (IRPF), é possível estimar que em 2012, os $50 \%$ brasileiros mais pobres detinham $2 \%$ da riqueza aqui produzida; $36,99 \%$ ficavam com $10,60 \%$; e $13,01 \%$ da população com $87,40 \%$ de toda economia produzida no país, sendo ainda uma parcela menor entre os mais ricos, $0,21 \%$, dona de $40,81 \%$ do total acumulado (AVILA, 2015). O fato é 
que enquanto uns viajam de jatinho ou helicóptero para cima e para baixo, outros viajam de burro ou pau de arara para fugir da seca, de enchente, do desemprego, da fome. Sim, em pleno século XXI, a fome é algo presente entre nós, uma nação com capacidade de produzir alimento suficiente para os seus e para os outros de fora. Dados da Pesquisa Nacional por Amostra de Domicílios (PNAD, 2010) revelam que mais de sete milhóes de brasileiros convivem em situaçôes críticas com a fome, isso equivale a 3,6\% da população brasileira.

A Constituição Federal do Brasil, a mais recente, de 1988, e diversos Decretos, Códigos e Estatutos asseguram ao cidadão e à cidadã, independente da idade, cor e gênero, uma vida no mínimo digna (BRASIL, 1988, Art. 18, 22, 23), com acesso à moradia, saúde, educação, cultura, segurança pública, além de autonomia econômica e, sobretudo, ideológica. Porém, a realidade que se perpetua nas mais de 5.500 cidades brasileiras está distante do que se preza nos direitos do cidadão brasileiro no tocante à erradicação da desigualdade social em nosso país, em constante crescimento econômico e político.

Mas estamos resistindo. Avançando. Nesses últimos anos, o Brasil reduziu 75\% da extrema pobreza que assola o país (FAO, 2014), saindo em 2014 do Mapa da Fome da Organização das Naçóes Unidas para Agricultura e Alimentação (FAO). Isso quer dizer que mais pessoas serão escolarizadas oficialmente, procurarão ter acesso ao conhecimento e terão mais força para lutar pelos seus direitos, sendo a democracia o maior de todos, inegociável. Hoje, temos até uma legislação específica sobre livro e leitura (BRASIL, 2013).

Desde a última Constituição foi vedado instituir impostos sobre livros, jornais, periódicos e o papel destinado a sua impressão (BRASIL, 1988, Art. 150), sendo permitida a entrada no país de livros em língua estrangeira ou portuguesa, imunes também de impostos (BRASIL, 2003, Lei 10.753/2003). No entanto, em país onde a desigualdade impera, os direitos são privilégios da classe dominante; nenhuma lei funciona sem aplicação consistente. Tudo tem que contribuir para o efetivo cumprimento dela, mesmo ela sendo, por vezes, contraditória e caótica; daí a importância de se conhecer o contexto da produção do texto da política, como esclarece Ball $(1994)^{1}$ e Bowe, Ball \&

1 Esse sociólogo da educação apresenta dois contextos para se entender os efeitos do jogo político: a) o contexto de resultados; e b) o contexto de estratégia política. É necessário conhecer esses dois eixos para que se tenha algum resultado quando se vai lutar politicamente contra injustiças e desigualdades sociais. 
Gold $(1992)^{2}$. Por aqui, o dia a dia prova e comprova que a nossa legislação beneficia quase que sempre aquele que tem maior poder aquisitivo. É preciso resistir a qualquer tipo de injustiça e perseverar pelos fundamentos do Estado Democrático de Direito: a soberania, a cidadania, a dignidade da pessoa humana, os valores sociais e da livre iniciativa, o pluralismo político, etc., segundo preconiza a Constituição (BRASIL, 1988, Art. 1, 3, 4).

Amenizando as questóes econômicas, que poderão ser consultadas em autores como Prado Junior (1986), exploraremos as de cunho cultural e educacional, que abarcam mais diretamente nosso foco de estudo, que é a formação leitora através de políticas públicas. No entanto, não perdendo de vista que "dentro das características de um país como o nosso, em que parte da população depende de programas assistenciais para as condiçóes básicas de sobrevivência, torna-se complicado o acesso aos livros por parte dos excluídos" (FERNANDES, 2007, p. 77).

\section{O Brasil de outrora: para se entender a crise leitora}

Historicamente estamos atrasados em questóes ligadas à educação, e isso não é segredo algum, sobretudo em relação à democratização do livro, da leitura e da literatura. Ainda há pouco, em 1900, tínhamos mais da metade da população analfabeta, sendo 65,3\% (INEP, 2000); em 2011 o Brasil contabilizava cerca de 13,9 milhóes de analfabetos adultos, ocupando a $8^{\circ}$ posição mundial (UNESCO, 2013) e, apesar dos expressivos números de alfabetizados, temos outros problemas tanto quanto ou mais grave que o analfabetismo absoluto que acometem nossas crianças e nossos jovens: o analfabetismo funcional, por exemplo, que inclusive está nas universidades públicas e privadas e em quase todas as classes econômicas, sobretudo nas classes $\mathrm{C}, \mathrm{D}$ e E.

Neste início de século, o Brasil possui algo em torno de $20 \%$ de analfabetos funcionais (INAF, 2012), brasileiros entre 15 e 49 anos. Mesmo havendo

2 Stephen Ball, juntamente com Bowe e Gold, explica a complexidade do jogo político a partir de ciclos, sendo esses sustentados em três contextos políticos primários, a saber: o contexto de influência, que é aquele em que as definiçóes políticas são iniciadas e os discursos políticos são construídos; o contexto da elaboração dos documentos das definiçóes políticas; e o contexto das práticas, que se refere aos territórios nos quais essas definições serão estabelecidas. É importante ter em mente que cada um desses contextos são instáveis. Para uma melhor compreensão e aprofundamento dessa temática, consultar os autores. 
uma redução de 13 pontos percentuais na comparação com o índice de 2001, $33 \%$, a taxa ainda é preocupante; entre os universitários essa percentagem chega a 38\% (INAF, 2012). Esses números tendem a crescer, tendo em vista as falhas do sistema básico de ensino no país e o modelo tradicional de aula que ainda sustentamos. Nenhuma lei funciona sozinha, é necessário um conjunto de açôes para que o cidadão possa estar bem consigo mesmo e com o que está a sua volta. Não adianta investir em políticas públicas incoerentes com a realidade da população. É necessário o tripé inicial: alimentação saudável, educação de qualidade e moradia digna; somente assim poderemos avançar, porque é na base que se rega uma planta e ela cresce saudável. Nesse sentido, Andréa Berenblum alerta que:

A leitura, como prática sociocultural, deve estar inserida em um conjunto de açôes sociais e culturais e não exclusivamente escolarizadas, entendida como prática restrita ao ambiente escolar. Portanto, pensar políticas de leitura extrapola o âmbito da escola - como locus e como função -, mas sem dúvida não pode prescindir dela, inclusive por ser a instituição pública das mais democratizadas - pela qual quase todos recentemente conseguem chegar e passar - ainda que, em muitos casos, descontinuamente e sem sucesso. (BERENBLUM, 2006, p. 23)

Lajolo \& Zilberman (2003) explicam que o Brasil só veio a demonstrar alguns traços necessários para a formação e fortalecimento de uma sociedade leitora a partir de 1840, quando aí se apresentavam os mecanismos mínimos, como tipografias, livrarias e bibliotecas, sendo a escolarização precária, contudo manifestando melhoria do sistema escolar. Nessa época, estávamos começando a conhecer a importância do conhecimento para o país; cabiam aos poucos autores literários o dever de conquistar leitores e lutar por espaços, que vinham sendo cultivados pelas leituras domésticas e coletivas. Não é à toa que até finais de 1900 o país contabilizava vergonhosamente mais de 70\% de analfabetos. Almeida (2000) revela que, em 1886, enquanto o Brasil possuía $1,8 \%$ da população escolarizada, a Argentina já contabilizava 6\%. Sobre o analfabetismo de 1534 a 1930 no Brasil, Freire (1993) tem um trabalho minucioso e surpreendente no qual critica as ideologias dominantes como 
responsáveis pelo atraso educacional. Os dados sobre a educação dessa época variam entre autores e governo, como se pode observar, mas no geral ficam dentro da margem de erro para mais ou para menos.

O problema do analfabetismo, da negação do outro, da ausência dos direitos civis no Brasil é algo historicamente intencionado, calculado e minuciosamente planejado pelas classes dominantes, desde tempos remotos. E não é algo isolado e deslocado, mas um conjunto de fatores tem contribuído e perpetuado para que tudo continue do jeito como foi construído, desenrolado e/ou arquitetado. Trata-se de um sistema arbitrário no qual estamos imersos. Muito mais do que manter o controle dos subordinados e excluídos sob seu domínio, a elite de países subdesenvolvidos, como o nosso, sente-se a todo instante ameaçada pelo desenvolvimento do outro. É preciso estar alerta porque o poder funciona e se exerce em rede, como diria Michel Foucault, sendo cada um de nós não apenas vítimas, mas também coautores, em algum momento, desses eventos. A questão está centrada na relação de poder, como explica Foucault (1979; 1996) através da sua tríade (poder - direito - verdade); poder não só do Estado ou da soberania, mas o poder das açóes sobre as açóes. Nosso maior inimigo é a falta de apropriação do saber, que se dá principalmente por intermédio do livro, da leitura e da literatura; é o desconhecimento ante o conhecimento que nos enfraquece; enfim, é a arbitrariedade da ignorância que nos rodeia e persegue a todo instante e em todos os lugares, inclusive na própria escola. Como disse Roberto DaMatta (1997, p. 237) “Fazer leis é, no Brasil, uma atividade que tanto serve para atualizar ideias democráticas quanto para impedir a organização e a reivindicação de certas camadas da população".

Em trabalho defendido por nós (BELO, 2014) no IX Congresso da Pós-Graduação em Língua Portuguesa da Faculdade de Formação de Professores da UERJ, realizado em 2014, vimos que até o século XVIII não se tinha sequer uma "língua definida” em terras brasileiras; o ensino de Língua Portuguesa tornou-se obrigatório nas poucas escolas que havia a partir da Reforma Pombalina, na década de 1750, sendo ministrada sob as formas de Retórica, Poética e Gramática. Findo o Império, em 1800, essas três disciplinas unificaram-se numa só que passou a se chamar Português. Até aí, o ensino de língua se sustentava na tradição gramatical e retórica e era direcionado aos grupos privilegiados socialmente, que tinham acesso à escola e já conheciam a "norma padrão culta", mas que precisavam do reconhecimento social (SOARES, 2001). 
Não muito distante, até a década de 1940 do século XX, a disciplina Língua Portuguesa manteve a tradição da gramática porque o público a que se destinava era o mesmo. Ou seja, nessa época "tem-se uma escola para alguns e um ensino de língua portuguesa que satisfaz aos seus interesses culturais. Os manuais didáticos da época apresentavam coletâneas de textos e bastante gramática, buscando preservar o 'bom gosto literário"” (SILVA \& CYRANKA, 2009, p. 275). Mas, com a democratização da escola, a partir da década de 1950, o ensino se volta para atender a grande demanda das classes populares. Segundo Geraldi (1991, p. 115), essa democratização "ainda que falsa” trouxe uma clientela diferente e multiplicada, gerando novas e bem diferentes condiçóes escolares e pedagógicas. $\mathrm{O}$ fato é que desde esse tempo, tem-se o conhecimento reservado para poucos, para os que detinham o poder. E que a democratização de acesso à educação é coisa recente no Brasil, ainda está acontecendo.

\section{O que dizem os dados oficiais}

A pesquisa Retratos da Leitura no Brasil (2011), promovida pelo Instituto Pró-Livro - IPL (2011), com apoio da Associação Brasileira de Editores de Livros (ABRELIVROS), da Câmara Brasileira de Livros (CBL) e do Sindicato Nacional de Editores de Livros (SNEL), revela que a média anual de livros lidos pelos brasileiros é de 4,0 por pessoa, lastimável quando comparado a outros países das Américas, como Chile, 5,4, e Argentina, 4,6, sem precisar citar os europeus. Dizem os dados que o Brasil é composto por $50 \%$ de leitores ou cerca de 88,2 milhóes de pessoas. Neste conceito, foram considerados leitores apenas as pessoas que leram pelo menos um livro, inteiro ou em partes, nos últimos três meses. Há também cerca de $50 \%$ nãoleitores. Por incrível que pareça, caímos em relação a 2007, quando líamos 4,7 livros. A pesquisa informa que $49 \%$ dos livros estão nas mãos de apenas $10 \%$ da população e que cada brasileiro compra, em média, 1,2 livro por ano. Estamos retrocedendo ao invés de avançar? A popularização do livro precisa ser mais bem discutida e o engajamento de todos é fundamental. A questão mais crítica, agora, não é de fator econômico, mas precisamente cultural; tanto que os dados dessa pesquisa ainda afirmam que $78 \%$ dos entrevistados têm o Desinteresse como a maior razão para estar lendo menos do que já leu, enquanto apenas $4 \%$ tem o Acesso como impedimento e 15\% Dificuldade de Leitura. 
Parece-nos que não há uma política efetiva de incentivo à leitura no Brasil, uma política de conscientização. $\mathrm{Na}$ verdade, isso até se explica pelo fato de que $85 \%$ dos brasileiros preferem assistir televisão a fazer qualquer outra atividade de lazer - aqui está uma das ferramentas que poderia mudar esse quadro, a TV. Mas ao invés de educar, a mídia brasileira, sobretudo a televisiva, massacra e aliena cruelmente seus telespectadores, formando uma legião de bestas domesticadas, para atingir suas metas capitalistas, de consumo que gira em torno da indústria cultural (ADORNO, 1987; MORIN, 1997). Há uma total deseducação por parte de nossa mídia, principalmente pelos canais abertos, salvo alguns poucos, que podem ser contados a dedo.

Por outro lado, vê-se nos olhos das crianças e dos jovens brasileiros a paixão pelo livro quando a eles são apresentadas possibilidades e oportunidades de interação com esse objeto, ainda que desconhecendo a complexidade funcional do livro, da leitura e da literatura, o cidadão brasileiro respeita e admira quem se envolve com o mundo da leitura e da escrita; concordamos com Viegas (2013, p. 19) que, através de pesquisa realizada, diz que há um discurso de valorização do livro por parte dos alunos e de seus familiares. Em visita a uma cidade do Agreste pernambucano, Pesqueira, no segundo semestre de 2012, por exemplo, pudemos verificar o interesse da comunidade com os livros literários ali apresentados e distribuídos por nós. $\mathrm{O}$ projeto $O$ livro está à mesa ${ }^{3}$ (BELO, 2012), financiado pela Fundação Nacional de Artes (Funarte), tinha como objetivo principal promover a cidadania cultural dos jovens de 17 a 29 anos. Realizamos visita às escolas da região, praças, igrejas, ponto de cultura e tribo indígena; o projeto popularizou o livro literário (poesia, romance, conto, teatro, etc.) naquela cidade, obras criteriosamente selecionadas, que valorizam a diversidade cultural brasileira e os aspectos locais, desde clássicos universais a

3 A Fundação Nacional de Artes - Funarte, com o objetivo de implantar as diretrizes traçadas pelo Programa Mais Cultura (regulamentado pelo Decreto no 6.226, de 04/10/2007), tornou público o Edital Mais Cultura: Microprojetos Rio São Francisco, que é voltado para municípios integrantes da Bacia do Rio São Francisco, em conformidade com a Lei no 8666/93, publicado no Diário Oficial da União em 10 de novembro de 2011. O Programa Mais Cultura de Apoio a Microprojetos teve como objetivo fomentar e incentivar artistas, produtores, grupos, expressóes e projetos artísticos e culturais. Entre as várias áreas apresentadas pelo Edital (Artes Visuais; Artes Cênicas; Música; Audiovisual; Artes e Expressóes Populares; Moda; etc.), o projeto O livro está à mesa, de nossa autoria, foi selecionado na área de Literatura, conforme publicado no Diário Oficial da União em julho de 2012, através da Portaria nº189. 
autores locais, como o poeta Audálio Alves (1930-1999). Nosso lema era "que, assim como o corpo precisa de alimento, a mente precisa de boas histórias".

Desde o século XVII o autor brasileiro dependia de outros países, sobretudo de Portugal e França, para produzir suas obras, ou ficava sem publicar, como Gregório de Matos, que ficou guardado na memória da população durante um bom tempo. Aliás, foi o visionário Monteiro Lobato, associado à empresa Olegário Ribeiro \& Cia., que funda a Olegário Ribeiro, Lobato \& Cia., editora que dura apenas alguns meses de 1919. Tendo fracassado nessa primeira tentativa, Lobato não desiste e segue em frente, associa-se no ano seguinte, 1920, com o jovem Octalles Marcondes Ferreira, e funda a primeira editora brasileira de alcance nacional - a "Monteiro Lobato \& Cia", o maior parque gráfico da América Latina já na década de 20 (PROJETO MEMÓRIA, 1998, pp. 6-8); foi ele quem, inclusive, pensou num sistema sério de distribuição a favor do livro e da leitura, um sistema inovador que incluía lombo de burro, barco e trem (SANT'ANNA, 2010, p. 10); livros que foram distribuídos às bancas de jornais, papelarias e armazéns (HALLEWELL, 2005, p. 320), ampliando a vendagem de livros das poucas livrarias, em torno de trinta na época, para mais de dois mil pontos de vendas de livros no país, dando início ao mercado livreiro e inserindo as pessoas no mundo da leitura e da literatura.

Hoje a situação é bem diferente, Lindoso (2004) explica que o Brasil tem a maior produção editorial da América Latina e é responsável por mais da metade dos livros editados no continente. A Câmara Brasileira do Livro (CBL) e o Sindicato Nacional dos Editores de Livros (SNEL) registraram mais de 750 editoras ativas no país em 2010 (RODRIGUES, 2011), enquanto foram contabilizadas em 2011, 3481 livrarias espalhadas nos vinte e sete estados brasileiros mais o Distrito Federal, sendo 1829 lojas somente na região Sudeste (ANL, 2012). Tendo em vista a quase inexistência de uma cultura livreira no país, e ainda a monopolização do mercado por parte de grandes redes que impedem o crescimento de pequenas livrarias e pontos de vendas, para quem publicam as editoras brasileiras? A mercantilização do conhecimento é outra séria problemática a ser discutida.

Escrevendo sobre a situação geral do papel desempenhado pelas editoras em várias regióes do mundo moderno, num artigo publicado pela Unesco, em 1997, Phillip Altbach (apud ODDONE, 1998, p. 30) registrou o seguinte 
[...] A atividade editorial tem uma importância que ultrapassa seu limitado papel econômico, porque ela é essencial à vida cultural, científica e educacional das naçóes. [...] A produção de livros - que reflete de maneira direta a cultura, a história e os interesses de uma nação ou de um povo - é algo que não pode ser transferido a terceiros. [...] Essa é uma parte vital de uma cultura. Nesse sentido, a atividade editorial é diferente, merecendo consideração especial. [...].

\section{(Re)pensando o livro, a leitura e a literatura}

No Brasil, as políticas públicas relacionadas ao livro, à leitura e à literatura são recentes, tanto que as açóes mais importantes do governo na área datam a partir de 1990, mas, sobretudo a partir de 2000. Algumas iniciativas podem ser vistas na década de 1930, frutos das mudanças econômicas, políticas e culturais que se apresentavam no país, mesmo diante do autoritarismo disfarçado, que possuía a centralização e o controle das práticas sociais.

O presidente Getúlio Vargas criou, sob o Decreto n. ${ }^{\circ}$ 19.402/1930, o Ministério da Educação ligado ao Ministério da Saúde, sendo denominado Ministério dos Negócios da Educação e Saúde Pública, que tinha como responsabilidade o estudo e despacho de todos os assuntos relativos ao ensino, saúde pública e assistência hospitalar; é a partir dessa década que a escola brasileira recebe os primeiros livros didáticos e conhece a leitura e a literatura. Em seguida, o Instituto Nacional do Livro foi criado, e tinha por objetivos

a) organizar e publicar a Enciclopédia Brasileira e o Dicionário da Língua Nacional, revendo-lhes as sucessivas ediçóes;

b) editar toda sorte de obras raras ou preciosas, que sejam de grande interesse para a cultura nacional;

c) promover as medidas necessárias para aumentar, melhorar e baratear a edição de livros no país bem como para facilitar a importação de livros estrangeiros

d) incentivar a organização e auxiliar a manutenção de bibliotecas públicas em todo o território nacional. (BRASIL, 1937, Grifo nosso) 
Na década de 80 foi instituído a "Semana Nacional do Livro e da Biblioteca" e o "Dia do Bibliotecário"; trata-se de um evento em que se consagrou como o "Dia Nacional do Livro", que já fora instituído em 1966, pela Lei n. ${ }^{\circ}$ 5.191. As comemoraçóes vinculadas ao livro e às bibliotecas são de responsabilidade do Ministério da Educação (MEC) através do Instituto Nacional do Livro (INL) com colaboração da Federação Brasileira de Associações de Bibliotecários e demais entidades e expressóes da vida nacional. O município de Passo Fundo, no Rio Grande do Sul, é hoje considerado a Capital Nacional da Literatura (Lei n. 11.264/2006). Outros eventos importantes foram constituídos e apoiados como políticas públicas, como o prêmio VivaLeitura ${ }^{4}$ e a participação do Brasil na Feira Internacional do Livro de Frankfurt, maior evento de livros do mundo, na Alemanha.

Em 1984 foi criado pela Fundação de Assistência ao Estudante (FAE) o Programa Nacional Sala de Leitura (PNSL), que tinha como trabalho compor, enviar acervos e repassar recursos para ambientar as salas de leitura. Uma variedade de livros de literatura e periódicos foi entregue aos alunos e professores. Esse programa foi realizado em parceria com as Secretarias Estaduais de Educação e com universidades responsáveis pela capacitação dos professores. Permaneceu até o ano de 1987.

Foi por meio da Lei n. 7.624/1987 que importantes órgãos culturais e educacionais foram instituídos, tais como a Fundação Nacional Pró-Leitura (PRÓ-LEITURA), a Fundação Nacional de Artes Cênicas (FUNDACEN)

4 Há um projeto de nossa autoria denominado Pelada literária, finalista desse Prêmio no ano de 2012 (DOU 16/08/12, Seção 3, pp. 16, 17), que consiste na mediação de leituras em campinhos de futebol, realizado sob os cuidados da Biblioteca Poeta Roberto Belo e aplicado numa periferia do Recife. Depois da publicação dos projetos finalistas no Diário Oficial da União (DOU) em 2013, a entrega do prêmio foi marcada e cancelada pelo menos quatro vezes, sendo notícia em alguns jornais de circulação nacional, uma vez que não se tinha uma explicação plausível sobre os cancelamentos. Por fim, nenhum dos finalistas chegou a receber o Prêmio VivaLeitura 2012 porque não houve premiação por ilegalidade por parte da direção, segundo nota divulgada pela Fundação Biblioteca Nacional, sendo o edital revogado (No do processo 01430.000.465/2012-13, DOU No 143, 29 de julho de 2014, Seção 3, p. 13). O mesmo projeto foi inscrito no edital de 2014, mas não foi contemplado. Diário de Pernambuco: <http://blogs.diariodepernambuco.com.br/politica/?p=27974>;Est adão:<http://cultura.estadao.com.br/noticias/geral,biblioteca-nacional-cancela-entrega-do-premio-vivaleitura,1099502>; SantoAndré:<http://www.santoandre.sp.gov.br/biblioteca/ bv/hemdig_txt/140129009m.pdf>; entre outros. 
e a Fundação do Cinema Brasileiro (FCB), sendo as finalidades da PRÓ-LEITURA, ainda que tímidas, importantes à época: “[...] I - promover o desenvolvimento da produção e da difusão do livro; II - estimular a publicação de obras de interesse cultural, a criação literária e a instituição de bibliotecas; III - difundir e estimular o hábito da leitura [...]" (BRASIL, 1988, Art. 2o).

Quatro anos depois, surge o Programa Nacional de Incentivo à Leitura (Proler), vigente até hoje. Instituído pelo Decreto n. 519, de 13 de maio de 1992, trata-se de um programa criado pela Fundação Biblioteca Nacional (FBN), do Ministério da Cultura (MinC), que tinha inicialmente o objetivo de possibilitar a toda comunidade, inclusive alcançando todos os segmentos da sociedade civil, o acesso a livros e a outros materiais de leitura. Seus principais objetivos são: promover o interesse nacional pelo hábito da leitura, estruturar uma rede de projetos capaz de consolidar, em caráter permanente, práticas leitoras e criar condiçôes de acesso ao livro. É mantido com recursos do orçamento da União, doaçóes e contribuiçôes nacionais e internacionais e pela participação financeira dos estados, do Distrito Federal e dos municípios através da FBN. É um programa interessante e bem elaborado, mas falta fiscalização em sua execução, ampliação de suas açóes e conscientização por parte dos municípios.

Através de uma parceria entre o MEC e o Governo francês, aparece o Pró-leitura na Formação do professor, um programa que se importava com a formação de professores leitores para que eles pudessem facilitar a entrada de seus alunos no mundo da leitura e da escrita. Inserido no Sistema educacional, propunha-se a articular os três níveis de ensino, envolvendo, em um mesmo programa, alunos e professores do ensino fundamental, os professores em formação e os pesquisadores. $\mathrm{O}$ programa aspirava estimular a prática leitora na escola pela criação, organização e movimentação das salas de leitura, cantinhos de leitura e bibliotecas (CEALE, 2009).

Ainda em 1992, vinculado ao MinC, foi criado o Sistema Nacional de Bibliotecas Públicas (SNBP) com o principal objetivo de fortalecimento das bibliotecas públicas por meio da "implantação de um processo sistêmico baseado em ações voltadas para a interação e integração dessas bibliotecas em âmbito nacional" (FBN, 2013). Para tanto, criou-se em cada estado brasileiro um Sistema Estadual de Bibliotecas Públicas, o qual, por sua vez, tem por meta articular as ações das diversas Bibliotecas Públicas Municipais. Atualmente, é 
de responsabilidade do SNBP o desenvolvimento das seguintes açóes: programa Livro Aberto, que propóe implantar bibliotecas em municípios que não as possuem e a revitalizar as já existentes; cadastro de bibliotecas públicas; capacitação e seminários; e assessoria técnica para as bibliotecas que fazem parte do sistema.

A Fundação Biblioteca Nacional (FBN) é uma fundação pública vinculada ao MinC com sede e foro na cidade do Rio de Janeiro. É o órgão mais potente do Governo, responsável pela execução da política governamental de recolhimento, guarda e preservação da produção intelectual do país. Possui um acervo com mais de 10 milhóes de itens, sendo por isso considerada pela UNESCO como a sétima maior biblioteca nacional do mundo e a maior biblioteca da América Latina. Sua trajetória histórica remonta à transferência da rainha D. Maria I, de D. João, Príncipe Regente, de toda a família real e da corte portuguesa para o Rio de Janeiro, quando da invasão de Portugal pelas forças de Napoleão Bonaparte, em 1808 (ver FBN, 2015, n.p.).

Recentemente também foi baixado o Decreto n. ${ }^{\circ} 7.748 / 2012$, que trata do seu estatuto, sendo revogado em 2014 pelo Decreto n. ${ }^{\circ}$ 8.297. Através desses documentos são esclarecidos e estabelecidos alguns objetivos e funçôes da instituição. É importante assinalar que a FBN possui órgãos específicos singulares: a Diretoria de Livro, Leitura, Literatura e Bibliotecas (DLLLB); o Centro Internacional do Livro; o Centro de Processos Técnicos; o Centro de Referência e Difusão; o Centro de Pesquisa e Editoração; a Biblioteca Demonstrativa Maria da Conceição Moreira Salles; e a Biblioteca Euclides da Cunha. Desses órgãos é interessante destacar alguns pontos da DLLLB:

Art. $8^{\circ}$ - [...] IV - formular, articular e implementar açóes que promovam a democratização do acesso ao livro e à leitura; [...] VIII - formular e implementar políticas, programas, projetos e açôes de criação e fortalecimento de bibliotecas e espaços de leitura; [...]

$\mathrm{X}$ - promover a literatura brasileira e fomentar os processos de criação, difusão, circulação e intercâmbio literário em território nacional e no exterior; [...]

XII - implementar açóes de fomento à literatura por meio de concessão de bolsas e prêmios a escritores brasileiros; 
XIII - articular com as secretarias e entidades vinculadas do Ministério da Cultura e demais órgãos do Governo federal a transversalidade das políticas de livro, leitura, literatura e bibliotecas; [...]. (BRASIL, 2014c)

Desde 2003 foi decretado pelo Congresso Nacional a Lei n. 10.753, que institui a Política Nacional do Livro. Lamentável saber que somente depois de 500 anos é que o Brasil instituiu uma política nacional a favor do livro. Ainda assim, trata-se de um avanço expressivo na área, tendo em vista suas diretrizes:

I - assegurar ao cidadáo o pleno exercício do direito de acesso e uso do livro;

II - o livro é o meio principal e insubstituível da difusão da cultura e transmissão do conhecimento, do fomento à pesquisa social e científica, da conservação do patrimônio nacional, da transformação e aperfeiçoamento social e da melhoria da qualidade de vida; [...]

$\mathrm{V}$ - promover e incentivar o hábito da leitura; [...]

VIII - apoiar a livre circulação do livro no país;

IX - capacitar a população para uso do livro como fator fundamental para seu progresso econômico, político, social e promover a justa distribuição do saber e da renda;

$\mathrm{X}$ - instalar e ampliar no país livrarias, bibliotecas e pontos de venda de livro; [...]

XII - assegurar às pessoas com deficiência visual o acesso à leitura. (BRASIL, 2013, p. 83)

Essa lei ainda determina que é de responsabilidade do Poder Executivo criar e executar projetos de acesso ao livro e incentivo à leitura, ampliar os já existentes e implementar, isoladamente ou em parcerias públicas ou privadas, as seguintes açóes em âmbito nacional:

[...] II - estimular a criação e execução de projetos voltados para o estímulo e a consolidação do hábito de leitura, mediante: 
a) revisão e ampliação do processo de alfabetização e leitura de textos de literatura nas escolas;

b) introduçấo da hora de leitura diária nas escolas;

c) exigência pelos sistemas de ensino, para efeito de autorização de escolas, de acervo mínimo de livros para bibliotecas escolares... (BRASIL, 2003, Art. 13º)

Nota-se a grandiosidade dessa Política Nacional do Livro, que é um marco na história leitora do Brasil. Vários eventos nacionais e internacionais têm sido realizados sob os cuidados dessa lei, cabendo tão somente à população nesse momento exigir seus direitos, fiscalizar o dinheiro gasto nos projetos e contribuir para o efetivo cumprimento da legislação. Em questão de educação, estamos aquém do esperado, não por falta de capital e determinações jurídicas, mas por falta de investimentos bem intencionados, sem falar nos desvios de verbas e projetos mal elaborados. Grandes empresas têm lucrado a base dessas políticas, tomando o mercado editorial ou livreiro, enquanto pequenas livrarias andam fechando as portas. Em Recife, tínhamos várias livrarias espalhadas pela cidade, temos hoje basicamente algumas redes gigantescas concentradas nos shoppings.

Em concordância com a Lei que instituiu a Política Nacional do Livro, foi lançado em 2011 o Plano Nacional do Livro e Leitura (PNLL), sob o Decreto n. ${ }^{\circ}$ 7.559/2011, que consiste em estratégia permanente de planejamento, apoio, articulação e referência para a execução de açóes voltadas para o fomento da leitura no país. Seus objetivos são:

I - a democratização do acesso ao livro;

II - a formação de mediadores para o incentivo à leitura;

III - a valorização institucional da leitura e o incremento de seu valor simbólico; e

IV - o desenvolvimento da economia do livro como estímulo à produção intelectual e ao desenvolvimento da economia nacional. (BRASIL, 2013, p. 179)

Trata-se de um plano bem elaborado, sendo sua implementação feita em regime de cooperação entre União, os estados, o Distrito Federal e os municí- 
pios; podendo ser as açôes realizadas com a participação de instituições públicas ou privadas, além de membros representativos da sociedade civil, autores, editores, do MinC e do MEC.

O PNLL está estruturado em quatro eixos estratégicos e dezenove linhas de ação, a saber: 1) eixo estratégico I - democratização do acesso; 2) eixo estratégico II - fomento à leitura e à formação de mediadores; 3) eixo estratégico III valorização institucional da leitura e de seu valor simbólico; e 4) eixo estratégico IV - fomento à cadeia criativa e à cadeia produtiva do livro. A partir desses eixos estabelecidos é possível visualizarmos uma política efetiva em prol do livro, da leitura e da literatura. O Decreto é recente, por isso cabe a nós, cidadãos e cidadâs, exigir o cumprimento dele e contribuir, enquanto sujeito ativo no processo, com ações afirmativas que se somem à concretização dessa política pública.

Segundo o Caderno do PNLL (2014, p. 35), cada órgão que compóe o Ministério da Educação desempenha uma função específica, cabendo ao Fundo Nacional de Desenvolvimento Educacional (FNDE), em parceria com a Secretaria de Educação Básica (SEB), Secretaria de Educação Continuada, Alfabetização e Diversidade e Inclusão (Secadi), "executar programas do livro e apoiar programas de leitura, por meio de convênios". Projetos e programas que se relacionem de forma transversal com a política setorial da área, caso daqueles referentes à cadeia produtiva do livro, como as açóes de exportação, desenvolvimento da indústria, apoio financeiro às pequenas e médias empresas, etc., serão desenvolvidos por outros ministérios e suas instituiçóes vinculadas a empresas estatais.

\section{Considerações finais}

Em suma, as políticas públicas atuais em relação ao livro e à leitura funcionam estrategicamente da seguinte forma: É de responsabilidade do Colegiado Setorial de Livro, Leitura e Literatura (CSLLL), o debate e a assessoria. Esse Colegiado está vinculado ao Conselho Nacional de Política Cultural, que foi instituído pelo Decreto no 5.520/2005, do MinC, decorrente da antiga Câmara Setorial de Livro, Leitura e Literatura. O CSLLL é na verdade,

[...] o instrumento de participação política na avaliação e monitoramento na execuçáo de políticas públicas de livro, leitura, literatura e bibliotecas. É o espaço de concertação para articula- 
ção, entendimentos e busca do consenso, sempre que possível, na implementação destas políticas públicas. É o espaço para a sociedade civil debater, defender e legitimar suas propostas para o setor. (CADERNO DO PNLL, 2014, p. 36)

Apesar do atraso decorrente da ordem de diversos fatores, adentramos, mesmo que tardiamente, a segunda década do século XXI fortalecidos na área. Estamos preparados, pelo menos politicamente, para pôr em prática açóes efetivas em relação ao livro, à leitura e à literatura. A população ainda está acuada, decerto, por falta de esclarecimentos, conscientização e popularizaçáo de alguns serviços. É de suma importância que os mais diversos espaços culturais sejam abertos ao cidadão, pois é um direito dele adentrar e se apropriar desses bens, sobretudo das bibliotecas, porque "o acesso ao livro e a preparação de uma sociedade de leitores é, com toda a certeza, mais um instrumento de inclusão econômica, social e política de dezenas de milhôes de brasileiros..." (PIVA \& PEREIRA, 2006, p. 50).

\section{Referências}

ADORNO, Theodor W. Televisão, consciência e indústria cultural. In: COHN, Gabriel (Org.). Comunicaçâo e industria cultural. São Paulo: T.A. Queiroz, 1987. ALMEIDA, José Ricardo Pires. História da instrução pública no Brasil, 15001889. São Paulo: Ed. da PUC/MEC/INEP, 2000. (Edição original em francês de 1889).

ANL. ASSOCIAÇÃO NACIONAL DE LIVRARIAS. Levantamento do Setor Livreiro 2012, http://gindre.com.br/wp-content/uploads/2012/05/levantamento_anual_20121.pdf, 11/05/2015.

AVILA, Róber Iturriet. Os dados da riqueza do Brasil e a estrutura tributária, 2015, http://brasildebate.com.br/os-dados-da-riqueza-do-brasil-e-a-estrutura-tributaria/, 11/05/2015.

BALL, Stephen Jefferson. Educational reform: a critical and post-structural approach. Buckingham: Open University Press, 1994

BELO, Roberto. O professor de língua portuguesa hoje. In: IX Congresso Internacional da Pós-Graduação em Lingua Portuguesa da UERJ: Português Língua do Mundo, 2014. Livro de Resumos. Rio de Janeiro: FFP/UERJ, 2014. v. 1. p. 17-18. 
BELO, Roberto. O livro está à mesa. Diário Oficial da União, DF, 26 de julho de 2012. Seção 1, p. 11.

BERENBLUM, Andréa. Por uma politica de formação de leitores. Brasília: MEC/SEB, 2006.

BOWE, R; BALL, S. J.; GOLD, A. Reforming education e changing schools: case studies in policy sociology. London: Routledge, 1992.

BRASIL. Lei n. ${ }^{\circ}$ 10.753, de 30 de outubro de 2003, Institui a Política Nacional do Livro. Presidência da República, 2003, http://www.planalto.gov.br/ ccivil_03/leis/2003/L10.753.htm, 10/04/2015.

BRASIL. Câmara dos Deputados. Legislação sobre livro e leitura. Brasília: Edições Câmara, 2013.

BRASIL. Constituição (1988). Constituição da República Federativa do Brasil. Brasília, DF: Senado Federal: Centro Gráfico, 1988.

BRASIL. Instituto Brasileiro de Geografia e Estatística (IBGE). Resolução n. ${ }^{o}$ 5, de 29 de dezembro de 2014. Diário Oficial da União, Brasília, DF, 30 de dezembro de 2014a, Seção 1, p. 110.

BRASIL. Ministério da Fazenda. Economia brasileira em perspectiva (Edição especial). Brasília, DF, 30 de dezembro de 2014b, p. 6, http://www.fazenda.gov.br/area-destaques/economia-brasileira-em-perspectiva-30.12.2014, $11 / 05 / 2015$.

BRASIL. Decreto n. ${ }^{\circ}$ 8.297, de 15 de agosto de 2014, Aprova o Estatuto e o Quadro Demonstrativo dos Cargos em Comissão e das Funçóes de Confiança da Fundação Biblioteca Nacional, 2014c, http://www2.camara.leg.br/legin/ fed/decret/2014/decreto-8297-15-agosto-2014-779231-normaatualizada-pe. pdf, 12/04/2015.

BRASIL. Decreto n. ${ }^{\circ}$ 95.674, de 27 de janeiro de 1988, Aprova o Estatuto da Fundação Nacional PróLeitura, e dá outras providências. Presidência da República, 1988, http:/www.planalto.gov.br/ccivil_03/decreto/1980-1989/ D95674.htm, 10/04/2015.

BRASIL. Decreto n. ${ }^{\circ}$ 93, de 21 de dezembro de 1937, Cria o Instituto Nacional do Livro. Câmara dos Deputados, 1937, http://www2.camara.leg.br/legin/ fed/declei/1930-1939/decreto-lei-93-21-dezembro-1937-350842-publicacaooriginal-1-pe.html, 10/04/2015. 
CADERNO DO PNLL: Edição atualizada e revisada em 2014. Ministério da Cultura. Brasília: MinC, 2014, http://www.cultura.gov.br/documents/10883/1171222/cadernoPNLL_2014ab.pdf/df8f8f20-d613-49aa94f5-edebfla7a660, 15/05/2015.

CANDIDO, Antonio. Vários escritos. Duas cidades: São Paulo, 2004.

CEALE. Centro de Alfabetização, Leitura e Escrita. [2009?] UFMG. PNBE - Programa Nacional Biblioteca da Escola: análise descritiva e crítica de uma política de formação de leitores, http://portal.mec.gov.br/dmdocuments/pnbe. pdf, 05/04/2015.

DAMATTA, Roberto. Carnavais, malandros e heróis: para uma sociologia do dilema brasileiro. Rio de Janeiro: Rocco, 1997.

FAO (Organização das Nações Unidas para Agricultura e Alimentação). $O$ estado da segurança alimentar e nutricional no Brasil: Um retrato multidimensional. (Relatório 2014). Brasília: FAO, 2014, https://www.fao.org.br/download/SOFI4_Brasil.pdf, 11/05/2015.

FBN. Fundação Biblioteca Nacional. Histórico. 2015, http://www.bn.br/biblioteca-nacional/historico, 05/04/2015.

FERNANDES, Célia R.; Delácio. Leitura, literatura infantojuvenil e educação. Londrina: EDUEL, 2007.

FOUCAULT, Michel. A ordem do discurso. São Paulo: Loyola, 1996.

FOUCAULT, Michel. Microfísica do poder. Organização e tradução de Roberto Machado. Rio de Janeiro: Ediçóes Graal, 1979.

FREIRE, Ana Maria Araújo. Analfabetismo no Brasil: da ideologia da interdição do corpo à ideologia nacionalista... São Paulo: Cortez, 1993.

GERALDI, João Wanderley. Portos de passagem. São Paulo: Martins Fontes, 1991.

HALLEWELL, Laurence. O livro no Brasil: sua história. [Trad. De Maria da Penha Villalobos, Lólio Lourenço de Oliveira e Geraldo Gerson de Souza] 2. ed. rev. e ampl. São Paulo: Editora da Universidade de São Paulo, 2005.

INAF - Indicador de Analfabetismo Funcional (INAF). Instituto Paulo Montenegro e a ONG Ação Educativa . IBOPE. 2012, http://www.ipm.org.br/ download/informe_resultados_inaf2011_versao\%20final_12072012b.pdf, $11 / 05 / 2015$. 
INEP. Instituto Nacional de Estudos e Pesquisas Educacionais Anísio Teixeira. Mapa do analfabetismo no Brasil. Brasília: INEP/MEC, [2000?], http://www. oei.es/quipu/brasil/estadisticas/analfabetismo2003.pdf, 08/04/2015.

LAJOLO, Marisa \& ZILBERMAN, Regina. A formação da leitura no Brasil. São Paulo: Ática, 2003.

LINDOSO, Felipe. O Brasil pode ser um pais de leitores?: Política para cultura/ Política para o livro. São Paulo: Summus Editorial, 2004.

MORIN, Edgar. Cultura de massas no século XX: neurose. Rio de Janeiro: Forence Universitária, 1997.

ODDONE, Nanci Elizabeth. Atividade editorial \& ciência da informação: convergência epistemológica. 1998. 266f. Dissertação (Mestrado em Ciência da Informaçáo) - Faculdade de Estudos Sociais Aplicados, Universidade de Brasília. Brasília, 1998.

PIVA, Monteiro; PEREIRA, Hamilton. Um estado de palavra. In: AMORIN, Galeno (Org.) Políticas públicas do livro e da leitura. Brasília: OEI; São Paulo: Cultura Acadêmica, 2006.

PNAD. PESQUISA NACIONAL AMOSTRA DE DOMICÍLIOS. Segurança Alimentar 2004/2009. Rio de Janeiro: Ministério do Planejamento, Orçamento e Gestão/IBGE, 2010, http://www.ibge.gov.br/home/estatistica/populacao/seguranca_alimentar_2004_2009/pnadalimentar.pdf, 15/05/2015.

PNUD (Programa das Naçôes Unidas para o Desenvolvimento). Relatório do Desenvolvimento Humano 2014. New York, USA, 2014, http://www.pnud. org.br/noticia.aspx?id=3909, 13/05/2015.

PRADO JUNIOR, Caio. História econômica do Brasil. São Paulo: Brasiliense, 1986. PROJETO MEMÓRIA. Monteiro Lobato: Vida, realidade e sonho. Brasília: Fundação Banco do Brasil/ODEBRECHT, 1998.

IPL. Retratos da Leitura no Brasil. São Paulo: Instituto Pró-Livro, 2011, http:// prolivro.org.br/home/images/relatorios_boletins/3_ed_pesquisa_retratos_leitura_IPL.pdf, 13/05/2015.

RODRIGUES, Maria Fernanda. Brasileiro compra mais livro, mas crescimento do setor é discreto. 2011, http://www.publishnews.com.br/telas/noticias/detalhes.aspx?id=64697, 10/04/2015.

SANT'ANNA, Affonso Romano. Anotaçóes para uma história da leitura. In: MARQUES NETO, José Castilho. (Org.). PNLL : textos e história. São Paulo: Cultura Acadêmica Editora, 2010. 
SILVA, Vanessa S.; CYRANKA, Lúcia F. M. A língua portuguesa ontem e hoje. In: Revista. Linhas críticas, Brasília, v. 14, n. 27, jul./dez. 2009, p. 271-287.

SOARES, Magda. Que professores de português queremos formar? In: Revista Movimento, n. 3, mai. de 2001, p. 149-155.

UNESCO . Organização das Naçôes Unidas para a Educação, a Ciência e a Cultura. Relatório de Monitoramento Global de Educação para Todos 2012: Juventudes e Habilidades colocando a educação em ação. Brasília: UNESCO, 2013.

VIEGAS, Maria F. da Silva. O Programa Nacional Biblioteca da Escola (PNBE) em quatro escolas da rede municipal de Porto Alegre. 2013. 96f. Trabalho de Conclusão de Curso (Graduação) do Instituto de Letras, Universidade Federal do Rio Grande do Sul, Porto Alegre, 2013.

\title{
PUBLIC POLICY OF ENCOURAGING THE BOOK, READING AND LITERATURE
}

\begin{abstract}
This paper aims to discuss some of the key laws and guidelines to encourage book reading and literature present in Brazilian society. Brazil has more than 202, 7 million inhabitants and it is considered the seventh largest economy in the world and the fifth largest country in area. He is one of the most unequal countries in the world, especially regarding the democratization of access to cultural goods, such as libraries.
\end{abstract}

KEYWORDS: literary literacy in Brazil; social inequality; educational public policies.

Recebido em: 30/10/2015

Aprovado em: 27/01/2016 